\title{
Problems of Orthopedically Impaired Students in Relation to their Gender, Achievement and Locality
}

\author{
Samir Kumar Lenka \\ Associate Professor in Education \\ TMIMT, Moradabad, UP \\ E-mail:samirlenka2@gmail.com \\ Ravi Kant \\ Assistant Professor in Education, \\ Maulana Azad National Urdu University \\ College of Teacher Education, Darbhanga, Bihar, India \\ E-mail: edu.ravikant@gmail.com
}

Doi:10.5901/jesr.2013.v3n2p249

\begin{abstract}
Orthopedically children are isolated from our society. They face many problems in their daily life. Due to continuous ignorance they become frustrate and some time hostile to the society. With using a sample of 100 orthopedically impaired children an attempt has made to identify the different social problems of these children in respect to their gender, achievement and locality. Result shows that gender plays no vital role on the social problems but female impaired children have more problem than male. High achiever student have less social problems in comparison to their counterparts. Locality has no significant effect on social problems but rural children have much more problem in comparison to urban children and this is due to unawareness and ignorance.
\end{abstract}

Keywords: Orthopedically impaired children, Social problems

\section{Introduction}

Orthos means straight and Paidios means child, which means the prevention of deformed adults lies in the development of straight children. Orthopedic impaired children are those children who suffer from such impairments of their muscle and skeletal and nervous system that may interfere with their normal functioning and adjustment to the journal and specified demand of their environment and thus making them orthopedic disable to the extent of requiring special measures for their well being, adjustment and educational progress. Orthopedic impairment, in general, constitute as one of most common or more prevalent physical impairment in the human being. In this way, all orthopedic impairments fall in the definition or category of physical impairments the reverse is not true. However, many (not all) physical disabilities are caused by orthopedic impairments. As a matter of distinction, all individual sufferings from orthopedic impairments according to world Health Organization exhibit difficulties in terms of locomotion, i.e., moving. That is why many times, the term locomotors impairment is also used in place of orthopedic impairment. Both the terms locomotors and orthopedic impairment have been variously define and explain by different writers and authorities. Let us reproduce a few important one for knowing the meaning and nature of condition known as orthopedic and locomotors impairment. According to Whitehouse Conference "The crippled child, in orthopedic sense is a child that has defect which cause a deformity or an interference with normal functions of bones, muscles or joints. The condition may be congenital or due to disease or accident, it may be aggravated by neglect or by ignorance." According to Public Law 94-142, "Orthopedically impaired means a severe orthopedic impairment which 
adversely affect a child's educational performance. The term includes impairments caused by congenital anomaly, impairment caused by disease and impairments from other causes."

Psychological characteristics of orthopedically children-

1. They are passive, less persistent, having shorter attention span, engage them in less exploration and display less motivation.

2. They are more dependent on adults and have high anxiety and frustration.

3. They are tender minded and somewhat tense.

4. Social relationships constitute a problem area for many crippled youngsters as they feel inferior and depressed.

5. They possess a poor ego and unconscious guilt feelings.

6. They have the strong sense of fear and lack confidence in their abilities.

Orthopedically children are also the part of our society but due to their physical impairment they are become isolate from main stream. In this study an attempt has made to identify their social problem.

\section{Litreature Reviewed}

Gray and Hendershot (2000) revealed that the emphasis was on a new view of disability i.e. not simply from the individual medical perspective, but also from a human rights and human development perspective. However, while clearly expanding on the previously body-centered notion of disability

Husain, Akbar (2006) in his research revealed that On the whole the level of self concept among the physically challenged adolescents was found significantly lower than their normal counterparts. Similarly the level of self concept among the girls was also found significantly lower than the boys in general, whereas category wise significant difference was found only in case of blind subjects.

Chandra Rakish and Koul Kabire (2006) revealed that no significant difference was found with respect to level of aspiration and level of education of visually impaired and orthopedic children and result also showed that no significant difference was found with respect to academic performance of visually impaired and orthopedically impaired children.

Narimani Mohammad \& Mousazadeh Tavakko (2010) Results indicted that impaired children had significantly less academic achievement as compared to the non-handicapped. The significant difference was also found, between the academic achievement of males and females.

Ahmed, Aqueel (2011) in his M.Phill dissertation found that the two groups of students i.e. physically challenged and normal secondary school students have been found to be significantly different on real self dimension of self concept inventory. The mean differences favors the normal group of secondary school students, which clearly indicates that normal group of secondary school students, have a high real self concept as compared to physically challenged secondary school students.

The findings of the study of Dinçyürek, Sibel etal. (2011) emphasize the importance of computer use by orthopedically impaired individuals for enhanced improvement of their condition. In addition, the findings stress the need for training well-educated experts who can use technology effectively to enable adaptations for individuals who need special education in the European Union.

Jena (2012) in his study found that School setting and educational level do not have significant effect on orthopedically handicapped adolescents perceived control, self-esteem and academic performance. However, integrated school students showed higher perceived control, self-esteem and academic performance than their counterparts in non-integrated school setting.

Kumar, Y and Pal, S (2012) in their study found that students are aware about the facilities provides by the Government to them and $53.26 \%$ physically challenged students were not aware about the facilities provided by the Government of them.

\section{Statement of Problem}

Problems of orthopedically impaired students in relation to their gender, achievement and locality. 


\section{Definition of Operational Terms Used}

Social Problems: Social problems are problems and difficulties that people often face in society. The term social problems refer to one's psychological development in and interaction with a social environment. social problems, which can greatly affect one's life, one's work, family and one's domestic life; can be mild to most severe in terms of how pervasive and to what extent a person exhibits the features of a personality disorder. Those with a social problem possess several distinct features including disturbances in self-image; inability to have successful interpersonal relationship; inappropriateness of range of emotions and ways of perceiving themselves, others and the world and differently possessing improper impulse control.

Orthopedic Impaired: The term orthopedic impairment refers to a severe physical impairment that adversely affects a child's learning and/or educational performance. This includes impairments caused by:

- Congenital anomaly; clubfoot, absence of some member, etc.

- Disease; poliomyelitis, bone tuberculosis, etc.

- Other causes; cerebral palsy, amputations, fractures or burns that cause contractures, etc.

A physical impairment frequently is identified in combination with other disabling conditions that often cause or contribute to the significant adverse effect on learning.

\section{Objectives of the Study}

1. To study the social problems of orthopedically students.

2. To study the social problems of orthopedically student on the basis of gender, achievement and locality.

\section{Hypotheses of the Study}

1. There exists no significant difference between boys and girls orthopedically impaired students on social problems.

2. There exists no significant difference between high and low academically achieved orthopedically impaired students on social problem.

3. There exists no significant difference between urban and rural orthopedically impaired students on social problem.

\section{Delimitations of the Study}

The study is limited to Moradabad and Bareilly commissionairy only. A sample of 100 students is taken for the study. The study is limited to 08-14 years of orthopedically impaired students only.

\section{Research Method}

In this study descriptive survey method was used.

\section{Population and Sample}

In this study all secondary school students for special need children of Moradabad and Bareilly commissionairy were considered as population. After these 100 secondary school students was selected as sample on the random basis.

\section{Tools Used}

For data collection, a variety of devices may be used keeping in view the suitability of the study. Therefore, selection of appropriate tools of vital importance for collection of data which depends on various considerations such as objectives of the study, availability of suitable tests and scales, personal competence of the investigator 
to administer, score and interpret the results. In this study self made questionnaire was used for the data collection.

\section{Analysis of Data}

The data gathered so far been analyzed through proper statistical techniques and results have been interpreted. Analysis and interpretation of the result is presented in following table-

Table 1:Significance of difference between boys and girls orthopedically impaired students on social problems

\begin{tabular}{llllllll}
\hline Variables & Groups & N & Mean & SD & SED & t- value & Level of significance \\
\hline Social Problems & Boys & 41 & 61.03 & 3.96 & 1.134 & 0.34 & Not significant \\
& Girls & 59 & 63.25 & 3.45 & & & \\
\hline
\end{tabular}

It is shown from the table 1 that the mean scores of boys and girls student with orthopedically impairment on the social problem are 61.03 and 63.25 with SD's 3.96 and 3.45 respectively. The t-ratio comes out to be 0.34 , which is not significant at any level of significance. That means there is no significant differences between boys and girls orthopedically impaired students on social problems. However the mean score of girls orthopedically impaired is higher than the boys' students. It implies that the girl's students have more social problems then the boys' students. Thus, the hypothesis 1 that 'there exists no significant difference between boys and girls orthopedically impaired students on social problem' is retained.

Table 2: Significance of difference between high and low academically achieved orthopedically impaired students on social problems

\begin{tabular}{llllllll}
\hline Variables & Groups & N & Mean & SD & SED & t-value & $\begin{array}{l}\text { Level } \\
\text { significance }\end{array}$ \\
\hline SocialProblems & High Achiever & 35 & 64.56 & 4.96 & 1.16 & 1.56 & Not significant \\
& Low Achiever & 65 & 67.25 & 5.25 & & & \\
\hline
\end{tabular}

It is shown from the table 2 the mean score of low and high academically achieved students with orthopedically impairment on the social problem are 64.56 and 67.25 with SD's 4.96 and 5.25 respectively. The tratio came out to be 1.56 , which is not significant at any level of significance. That means there is no significant difference between high and low academically achieved orthopedically impaired students on social problem. However the mean score of low academically achieved orthopedically impaired is higher than the high academically students. It implies that low academically achieved students have more social problems than their counterparts. Thus, the hypothesis 2 'there exists no significant differences between high and low academically achieved orthopedically impaired students on social problems' is retained.

Table 3: Significance of difference between urban and rural orthopedically impaired students on social problems

\begin{tabular}{llllllll}
\hline Variables & Groups & N & Mean & SD & SED & t- value & Level of significance \\
& & & & & & & \\
\hline SocialProblems & Urban & 37 & 66.26 & 5.96 & 1.56 & 1.49 & Not significant \\
& Rural & 63 & 68.95 & 5.25 & & & \\
\hline
\end{tabular}

It is shown from the table 3 that the mean scores of rural and urban students with orthopedically impairment on the social problem are 66.26 and 68.95 with SD's 5.96 and 5.25 respectively. The t-ratio comes out to be 1.49 , which is not significant and any level of significant. That means there is no significant difference between rural and urban students with orthopedically impairment on social problem. However, the mean scores of rural orthopedic impaired students is higher than the urban students. It implies that the rural students have 
more social problem then the rural students. Thus the hypothesis 3 'there exists no significant difference between rural and urban orthopedically impaired students on social problem' is retained.

\section{Main Finding}

1. There is no significant difference between boys and girls students with orthopedically impaired students on social problem. Further the girls' students have more social problem than the boys' students.

2. There is no significant difference between high and low academically impaired students with orthopedically impaired students on social problem. Further the low academically achieved orthopedically impaired students have more social problems than the high academically achieved students.

3. There is no significant difference between urban and rural students with orthopedically impaired students on social problem. Further the rural students have more social problems than the urban students.

\section{References}

Ahmed, Aqueel (2011) A Study of Self Concept, Level of Aspiration and Academic Achievement of Physically Challenged and Normal Students at Secondary Level in District Baramulla, Unpublished dissertation, University of Kashmir.

Best J.W. (1977). Research in Education, Englewood cliffs, New Jersey: Prentice Hall Inc.

Best, J.W. \& Kahan, J.V. (1996). Research in Education (7th ed.). New Delhi: Prentice Hall Inc.

Chandra Rakish and Koul, Kabire (2006) Comparative Analysis of Visually Impaired and Orthopedically Handicapped Children on Academic Performance, Level of Education and Level of Aspiration in Northern Assam, 5th Survey of Research in Education, New Delhi: NCERT.

Gray, D. B. \& Hendershot, G. E. (2000). The ICIDH-2: Developments for a new era of outcomes research. Archives of Physical Medicine and Rehabilitation, 81 (Suppl 2), S10-S14.

Hallahan, P.D. \& Kauffman, J.M., (1988). Exceptional children, USA: Prentice-Hall International, 471-477.

Hannell, G. (2006) Identifying children with special needs: Checklists and action plans for teachers. Thousand Oaks, CA: Corwin Press.

Husain, Akbar (2006) Self Concept of Physically Challenged Adolescents, Journal of the Indian Academy of Applied Psychology, 32(1), 43-46.

Jena, Prakash Chandra (2012) Perceived Control, Self-Esteem and Academic Performance of Orthopedically Handicapped Adolescents in Integrated and Non-Integrated School Setting. International Educational E-Journal, 1(3), 32-49.

Kumar Yatendra and Pal S (2012) A Study of Awareness of Facilities Provided To Physically Challenged Students. International Indexed \& Referred Research Journal; 4(41), 34-35.

Narimani Mohammad \& Mousazadeh Tavakko (2010) Comparing self-esteem and self-concept of handicapped and normal students. Comparative study of Self-esteem and Self-concept of Handicapped and Normal Students. Journal of Behaioural Psychology, 9(308).

Sibel DİNÇYÜREK, Nihan ARSAN and Mehmet CAĞLAR (2011) the orthopedically handicapped and computer usage: the case of trnc, TOJET: The Turkish Online Journal of Educational Technology, 10(1), 209-215.

Umadevi, M R (2010) Special Education- A practical approach to educating children with special needs, Neelkamal Publication, Hyderabad, p-280. 
